\title{
Automated Monitoring of Soil Respiration: an Improved Automatic Chamber System
}

\author{
Gemini Delle Vedove ${ }^{1}$, Giorgio Alberti ${ }^{*}$, Michel Zuliani ${ }^{1}$, Alessandro Peressotti ${ }^{1}$, \\ Ilaria Inglima ${ }^{2}$, Giuseppe Zerbi ${ }^{1}$ \\ ${ }^{1}$ Dipartimento di Scienze Agrarie ed Ambientali, Università di Udine \\ Via delle Scienze 208, 33100 Udine, Italy \\ ${ }^{2}$ Dipartimento di Scienze Ambientali, Seconda Università di Napoli \\ Via Vivaldi 43, 81100 Caserta, Italy
}

Received: 23 June 2007. Accepted: 9 September 2007.

\begin{abstract}
We designed, constructed and tested an automated chamber system for continuously monitoring soil respiration. Our objective was to design a system that would permit monitoring of $\mathrm{CO}_{2}$ efflux rates over long time periods without altering microclimate inside the chamber. The measuring principle is based on the measurement of the increase in $\mathrm{CO}_{2}$ concentration within an automated chamber in a fixed amount of time using a non linear regression method. The chamber operates by closing over the soil in response to a control signal and remains closed for a fixed amount of time. In this way, the chamber allows normal drying and wetting of the soil between measurements. We report results that show the reliability of soil $\mathrm{CO}_{2}$ efflux measurements in comparison with Li-Cor 6400 . The system holds great potential for long term continuous measurements campaigns in natural environments.
\end{abstract}

Key-words: soil respiration, continuous measurements, soil chambers.

\section{Introduction}

Soils store the largest $\mathrm{C}$ pool in terrestrial ecosystems (Schlesinger, 1997) and the fate of such pool depends ultimately on the balance between processes controlling soil $\mathrm{C}$ input (i.e. primary production, belowground $\mathrm{C}$ allocation, littering) and output (i.e. litter decomposition, soil $\mathrm{CO}_{2}$ efflux, leaching of dissolved C). Soil Respiration (SR) is the outgoing flux of $\mathrm{CO}_{2}$ from the soil to the atmosphere $\left(\mu \mathrm{mol} \mathrm{CO} \mathrm{CO}^{-2} \mathrm{~s}^{-1}\right)$; it is the sum of $\mathrm{CO}_{2}$ fluxes coming from roots and rizosphere microbial respiration, the so called autotrophic respiration, plus the $\mathrm{CO}_{2}$ produced by the soil biota decomposing soil organic carbon (heterotrophic respiration). There is a third component of SR referring to $\mathrm{CO}_{2}$ coming from dynamic equilibrium of carbonates salts in soil solution. After photosynthesis, soil respiration is the second largest flux of carbon in most ecosystems. Thus, the current emphasis on ecosystem management for increased $\mathrm{C}$ sequestration requires an improvement in knowledge of soil respiration processes. The soil $\mathrm{CO}_{2}$ fluxes can be measured by a variety of techniques but each technique can influence the apparent rates of respiration. Livingston and Hutchinson (1995) distinguished three different chamber techniques to measure soil respiration: closed static system, closed dynamic system and open dynamic system. In the first two types, the soil $\mathrm{CO}_{2}$ efflux is estimated measuring the rate at which $\mathrm{CO}_{2}$ increases within a chamber that has been placed on the soil for a certain amount of time. In the open dynamic system, the efflux is calculated as the difference between the $\mathrm{CO}_{2}$ concentration at the inlet and the outlet of the chamber knowing the air mass flow going through. At the moment, no single method has been established as a standard (Pumpanen et al., 2004). Comprehensive reviews of the advantages and disadvantages of each type of sys-

\footnotetext{
* Corresponding Author: Tel.: +39 0432 558597; Fax: +39 0432 558603. E-mail address: alberti@uniud.it.
} 
tem can be found in literature (Livingston and Hutchinson, 1995; Hutchinson and Livingston, 2002; Davidson et al., 2002; Kutsch at al., 2004). The primary problem for measurement of SR is the high spatial and temporal heterogeneity in the rates of soil $\mathrm{CO}_{2}$ efflux (Xu and Qi, 2001). In fact, the soil $\mathrm{CO}_{2}$ efflux can vary in response to soil temperature, soil water content and photosynthetic $\mathrm{C}$ input. In order to better understand the processes influencing $\mathrm{CO}_{2}$ emissions from soils and to handle spatial and temporal heterogeneity, long term continuous measurements, based on automatic soil respiration systems, are required. These automatic systems are usually expensive and require continuous maintenance. Our objective was to develop, construct and test an automated closed dynamic system that will provide high temporal resolution measurements of soil $\mathrm{CO}_{2}$ efflux over long period of time. In the present paper, we describe the system and we assess the reliability of $\mathrm{CO}_{2}$ efflux measurements by comparison of this system with a conventional closed dynamic through flow chamber system (Li-Cor 6400 gas analyzer analysis console with Li6400-09 soil chamber) that was used as reference since it was shown to accurately measure $\mathrm{CO}_{2}$ efflux rates (Pumpanen et al., 2004). Because soil $\mathrm{CO}_{2}$ efflux is driven by diffusion and mass flow with the diffusion being controlled by $\mathrm{CO}_{2}$ gradient and mass flow by pressure fluctuation at the soil surface, wind is one of the most important contributors to surface pressure fluctuations (Hutchinson and Mosier, 1981; Takle et al., 2004). In fact, under windy conditions, higher soil $\mathrm{CO}_{2}$ efflux might be expected but few dataset in literature support this conclusion (Baldocchi and Meyers, 1991; Takle et al., 2004; $\mathrm{Xu}$ et al., 2006). In the present paper we also tested the influence of wind speed on the measured effluxes.

\section{Materials and methods}

\subsection{The system}

The system we developed can be classified as a closed dynamic system according to Livingston and Hutchinson (1995) and can manage up to twelve soil respiration chambers.

Each chamber consists of a steel collar (20 $\mathrm{cm}$ of diameter and $8 \mathrm{~cm}$ height) and an DC

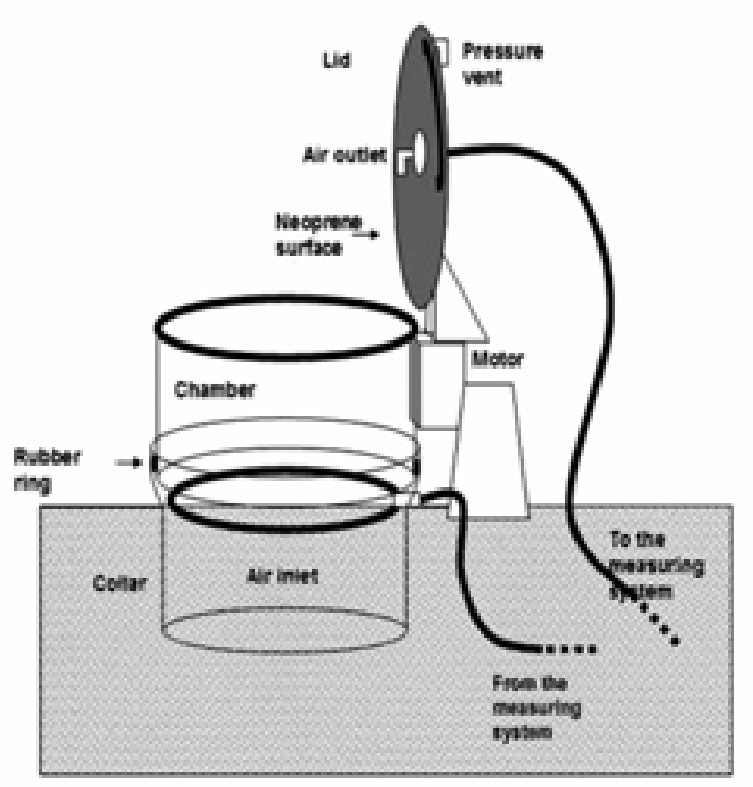

Figure 1.A. A drawing of the soil respiration chamber shown in the open position.

motor closing steel lid (it require $140 \mathrm{~s}$ to completely close), is placed on a steel collar inserted into the soil and the lid, when open, is in vertical position on North side of the collar to avoid shadowing (Fig. 1.A). Tightness of the lid closure is ensured by a neoprene cover on the inner surface of the lid and a rubber ring covering the top perimeter of the collar. The air is sampled from the centre of the lid and is returned by a manifold inside the collar. The connection between the chamber and the measuring system is realized with high density PVC tubing (10 m long, 4/6 $\mathrm{mm}$ inner/outer diameter). To avoid air pressure difference between inside and outside the chamber, a pressure vent was built according to the indication of $\mathrm{Xu}$ et al. (2006) and placed on the top of the chamber (Hutchinson and Livingston, 2001). The adopted vent design allows static pressure changes inside the chamber to follow whatever static pressure changes occur in the surrounding air outside the chamber both in calm and windy conditions while remaining insensitive to wind direction (Xu et al., 2006).

During the operation, air is circulated between the soil chamber to an infrared gas analyzer (IRGA, SBA-4, PP-Systems) at a constant flow rate $\left(0.51 \mathrm{~min}^{-1}\right)$. Air humidity, pressure and temperature are measured using the addi- 
tional sensors provided by the PP-System with the IRGA and are acquired by parsing the digital output of the analyzer. The sequential sampling from the chamber is electronically controlled by a datalogger (CR1000 Campbell Sci. Inc. Lincoln Nebraska - USA) and a 16 channel AC/DC controller (SDM CD16-AC, Campbell Scientific) through the stimulation of couples of solenoids valves connected to the inlet and outlet of each chamber. When one pair of valves opens, the closure of the lid of the corresponding chamber is initiated by the software. The system is also equipped with a GSM base for remote control and data download.

The measuring principle is similar to the one used by the Li-Cor 8100 Automated Soil $\mathrm{CO}_{2}$ Flux System (Li-Cor, Lincoln, NE, USA): the system uses the rate of increase of $\mathrm{CO}_{2}$ within the chamber to estimate the rate at which $\mathrm{CO}_{2}$ diffuses into free air outside the chamber. Atmospheric $\mathrm{CO}_{2}$ is measured every second during lid closure and the final value $\left(C_{0}, \mu \mathrm{molCO}_{2}\right.$ $\mathrm{mol}^{-1}$ of dry air) is recorded as the average of the last ten observations before lid closure (16 $\mathrm{sec})$. After closure, $\mathrm{CO}_{2}$ concentration $(C$, $\mu$ mol$\mathrm{CO}_{2} \mathrm{~mol}^{-1}$ of dry air), water vapour mole fraction $\left(W, \mathrm{mmol} \mathrm{mol}{ }^{-1}\right)$, air temperature $\left(T,{ }^{\circ} \mathrm{C}\right)$ and air pressure $(P, \mathrm{kPa})$ within the chamber are recorded using a RS-232 connection by the CR1000 every 1.6 second till chamber re-opening (Fig. 1.B).

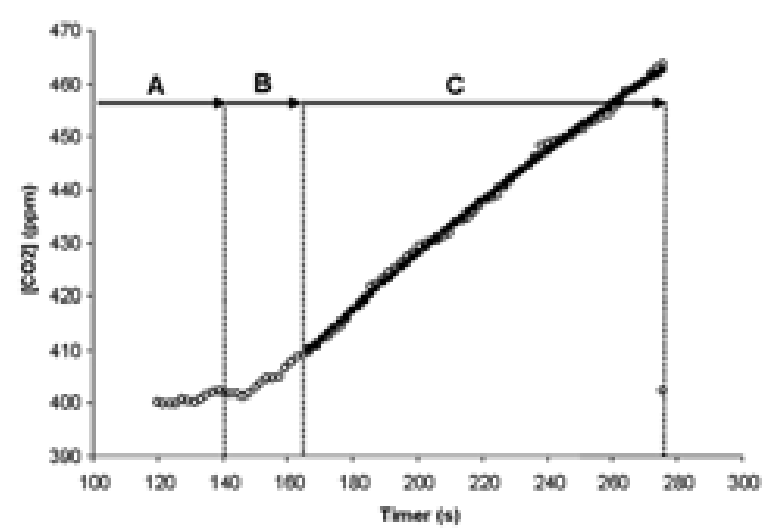

Figure 1.B. Principle of the measurement: chamber closure from 0 to $140 \mathrm{~s}$ and measure of the $\left[\mathrm{CO}_{2}\right]$ target as the average of the last 10 measures (A); mixing for $23 \mathrm{~s} \mathrm{(B);} \mathrm{non-}$

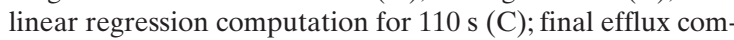
putation after $275 \mathrm{~s}$. Open symbols are measured $\mathrm{CO}_{2}$ concentrations; closed symbols are derived values from the computed non-linear regression.
To minimize the underestimation of the efflux due to the alteration of the diffusion gradient, we used a nonlinear curve fitting (Davidson et al., 2002; LI-COR, 2004): when a steady chamber mixing is established after lid closure (typically after 30-40 s) a non linear regression between $\left[\mathrm{CO}_{2}\right]$ and time is performed according to the equation (Fig. 1.B):

$$
C(t)=C_{\mathbf{x}}-\left(C_{\mathbf{x}}-C_{\mathbf{0}}\right) e^{-\mathbf{a}(\mathbf{t}-\mathbf{t} \mathbf{0})}
$$

where $C(t)$ is the $\mathrm{CO}_{2}$ concentration corrected by the water mole fraction, and $C_{\mathbf{x}}$ and $a$ are estimated regression's parameters, $C_{\mathbf{0}}$ is the initial concentration at chamber closure, $C_{\mathbf{x}}$ is the asymptote, and $a$ is the parameter which defines the curvature: positive if $C_{\mathbf{x}}>C_{\mathbf{0}}$ or negative otherwise, $t_{0}$ represents the time when $C(t)$ is equal to $C_{0}$. The regression coefficients $C_{\mathbf{x}}, C_{\mathbf{0}}$ and $a$ are calculated by the data logger using a non linear regression by a modified Gauss Newton iterative method. The initial rate of change in $\mathrm{CO}_{2}(d C / d t)$ at $C_{\mathbf{0}}$ and $t_{0}$ is computed using the equation:

$$
d C / d t=a\left(C_{\mathbf{x}}-C_{\mathbf{0}}\right) \mathrm{e}^{-\mathrm{a}(\mathrm{t}-\mathrm{t} 0)}
$$

Then, the Soil $\mathrm{CO}_{2}$ efflux ( $\mu$ mol $\mathrm{CO}_{2} \mathrm{~m}^{-2} \mathrm{~s}^{-1}$ ) is computed using the following equation:

$$
S R=\frac{V}{S} \cdot \frac{d C}{d t} \cdot \frac{P_{0}}{R \cdot\left(T_{0}+273.15\right)}
$$

where $P_{0}$ and $T_{0}$ are the air pressure and air temperature measured as average of the last ten measure before lid closure; $R$ is the universal gas constant $\left(8.31 \mathrm{~J} \mathrm{~mol}^{-1} \mathrm{~K}^{-1}\right), V$ is system volume $\left(\mathrm{cm}^{3}\right)$ and $S$ is chamber basal area $\left(\mathrm{cm}^{2}\right)$.

\subsection{Field tests}

We performed a comparison with the Li-Cor 6400 in order to assess the reliability of our system and a continuous long term monitoring of soil $\mathrm{CO}_{2}$ efflux to study the influence of some environmental variables on the efflux. The site where both the tests were conducted is a corn field and is located in the Eastern part of Italy $\left(46^{\circ} 00^{\prime} \mathrm{N}, 13^{\circ} 01^{\prime} \mathrm{E}\right)$. The soil has a bulk density of $1.1 \mathrm{~g} \mathrm{~cm}^{-3}$, a stoniness of $21 \%$ in weight and an organic carbon content of $22 \mathrm{tC} / 1500$ $\mathrm{t}$ of soil. The system was set up in the field at the beginning of September 2006. The compar- 
ison with the Li-Cor 6400 was performed two weeks after harvesting on $17^{\text {th }}$ October 2006 between 8:00 to 16:00, while the continuous long term test of the system was performed at the same site from $17^{\text {st }}$ October to $1^{\text {st }}$ December 2006. During the comparison, the system was programmed to perform two cycles (two measurements on each chamber) every two hours; for the long term test, only one cycle was performed every 2 hours. One cycle lasted half an hour and then the second took place. The measurement with the Li-Cor 6400 was done after the chamber re-opening by placing the Li-Cor chamber on the soil within our system's chamber and performing three consecutive cycles. During the comparison, 40 measurements were taken (5 chambers $\mathrm{x} 2$ cycle $\mathrm{x} 4$ sessions).

\subsection{Influence of wind}

The pressure of a flowing fluid, $\mathrm{P}$, is related to the density, $\rho$, and velocity, $V$, according to the equation:

$$
P+0.5 \rho V^{2}=\text { constant }
$$

If we applied this equation to the vented chamber where the velocity of the air at the vent is the wind speed, $V_{\mathbf{1}}$, and the velocity at the end of the tube connected to the vent inside the chamber is $V_{2}$ which is also that at the ground surface outside the chamber and equals zero, the pressure difference $\left(P^{\prime}\right)$ is:

$$
P^{\prime}=P_{\mathbf{2}}=P_{\mathbf{1}}=0.5 \cdot \sigma \cdot V_{1}^{2}
$$

for $\rho=1.2 \mathrm{~kg} \mathrm{~m}^{-3}$ and with $V_{\mathbf{1}}$ in $\mathrm{m} \mathrm{s}^{-1}$, we obtain

$$
P^{\prime}=0.6 \cdot \sigma \cdot V_{1}^{2}
$$

in $\mathrm{Pa}$. We measured wind speed at $20 \mathrm{~Hz}$ interval using a Young anemometer placed at $3 \mathrm{~m}$ height at a nearby eddy covariance tower. The measured wind speed was used to estimate wind speed at $0.15 \mathrm{~m}$ above the soil using the relationship:

$$
V=\frac{u^{*}}{0.4} \cdot \ln \cdot\left(\frac{(0.15-d)}{z_{m}}\right)
$$

where $u^{*}$ is the friction velocity, $d$ is the zero place displacement and $z_{\mathrm{m}}$ is the momentum roughness parameter. The hourly mean of $V(0.15)$ was then computed.

\section{Results and discussion}

Weather conditions during the comparison session between the two systems are reported in Figure 2: air temperature ranged between $6{ }^{\circ} \mathrm{C}$ at night and $19{ }^{\circ} \mathrm{C}$ at midday, air humidity during the experiment was around $30-40 \%$ and soil water content $(\% \mathrm{v} / \mathrm{v})$ measured with five TDR sensors was stable and around $21 \%$. Over the $\mathrm{CO}_{2}$ efflux range of $0.5-4.0 \mu \mathrm{mol} \mathrm{m} \mathrm{m}^{-2} \mathrm{~s}^{-1}$, the two system showed significant agreement at each chamber especially at low rates (Fig. 3.A; P < $0.001)$, but on average, the system we proposed overestimates the efflux by about $10 \%$ in comparison to LiCor 6400. However, the means of effluxes measured at the five chambers show a
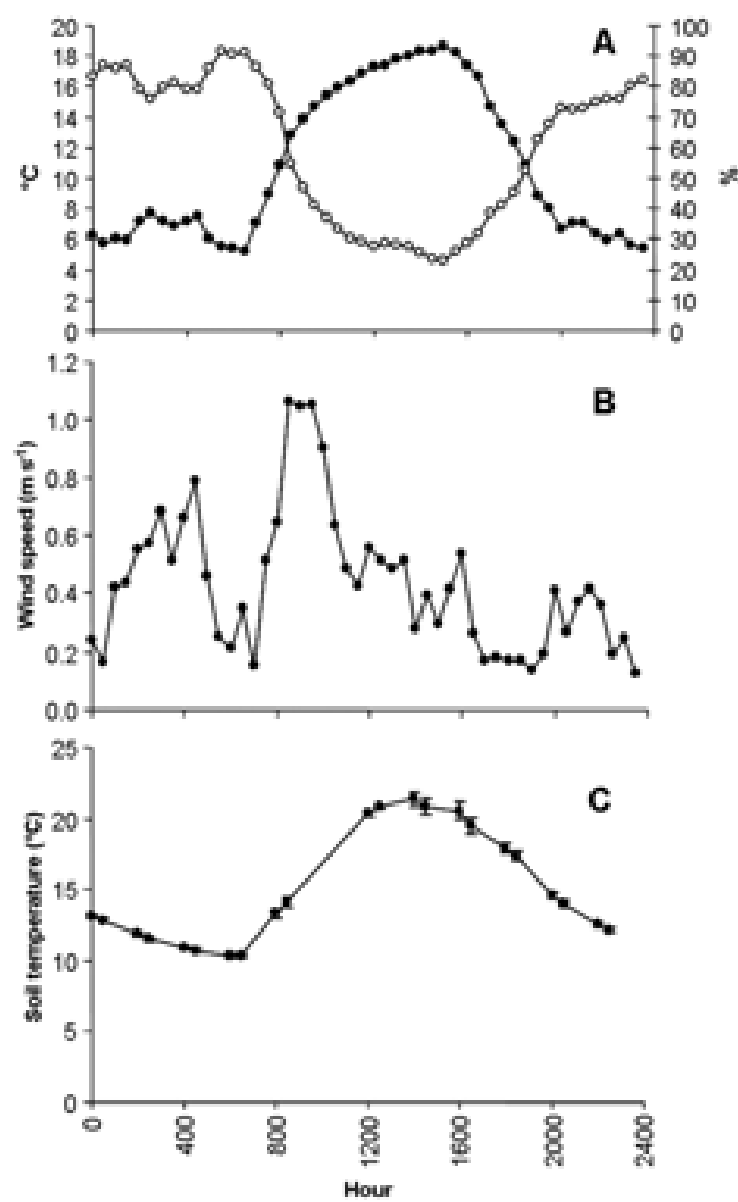

Figure 2. Air temperature and relative humidity (A), calculated wind speed at $0.15 \mathrm{~m}$ (B) and soil temperature (C) during the comparison between the two systems. Bars for the soil temperatures are standard error $(n=5)$. Measures are half-hourly average. 

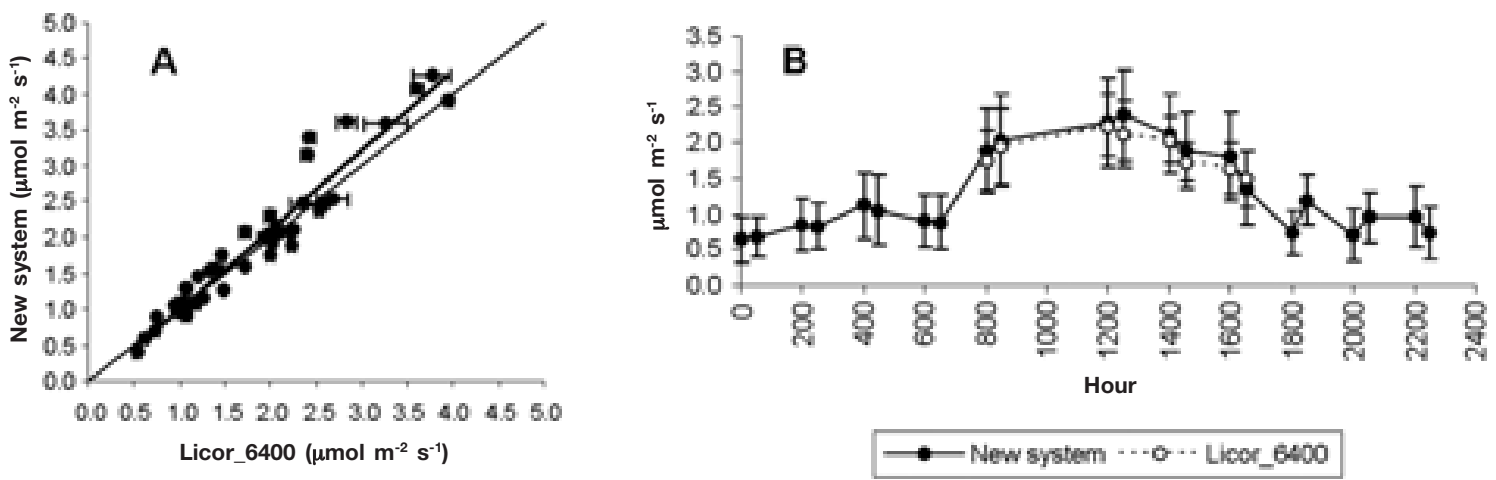

Figure 3.A. Soil $\mathrm{CO}_{2}$ efflux as measured by the new system plotted against fluxes measured by the Li-Cor 6400 system (slope: 1.10; intercept: $-0.08 ; \mathrm{n}=40 ; \mathrm{R}^{2}=0.92 ; \mathrm{P}<0.001$ ). Data points represent one measurement taken with the new system and the average of three consecutive cycles taken by the Licor 6400. Bars are standard errors $(n=3)$. Figure 3.B. Efflux daily trend as measured by the two systems. Bars are standard errors $(\mathrm{n}=5$ chambers $)$.

good agreement between the two system in terms of daily trend (Fig. 3.B).

The system worked properly during all the long term experiment period: some data gaps were only due to maintenance or very severe

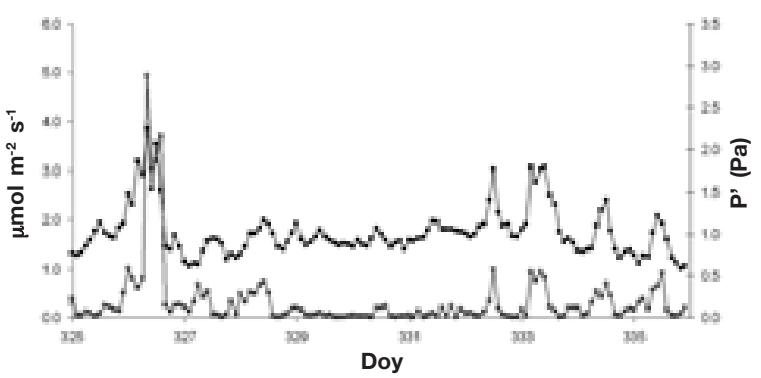

Figure 4.A. Soil respiration and pressure fluctuation ( $\left.\mathrm{P}^{\prime}\right)$ induced by wind at the experimental site from $21^{\text {st }}$ November 2006 (doy 325) to $2^{\text {nd }}$ December 2006 (doy 336). Each point is the average of data recorded during one measuring cycle.

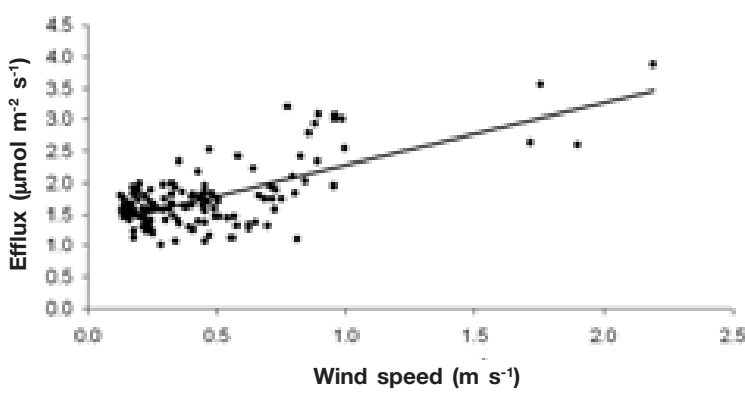

Figure 4.B. Soil respiration as function of mean wind speed at vent height from 21 $1^{\text {st }}$ November 2006 (doy 325) to $2^{\text {nd }}$ December 2006 (doy 336). Each point is the average of data recorded during one measuring cycle (slope $=0.99$, intercept $\left.=1.30, \mathrm{R}^{2}=0.46, \mathrm{n}=132, \mathrm{P}<0.001\right)$.
Table 1. Summary of the system performance during the long term test (from $17^{\text {th }}$ Octber to $1^{\text {st }}$ December 2006). One measurement cycle was performed every two hours.

\begin{tabular}{lrr}
\hline Number of expected cycles & 528 & \\
Number of recorded cycles & 493 & $93 \%$ \\
Number of high quality data & 2379 & $90 \%$ \\
Number of discarded data & 261 & $10 \%$ \\
Total number of recorded data & 2640 & $100 \%$ \\
\hline
\end{tabular}

storms when the system was turned off, remotely. As far as the data quality is concerned, 261 efflux measurements on $2640(10 \%)$ have been discarded because the regression was not good or the analyzer did not work properly (Tab. 1). During the field testing, higher soil $\mathrm{CO}_{2}$ fluxes were recorded whenever there was wind during the measurement period. In figure 4.a and 4.b the correlation between soil $\mathrm{CO}_{2}$ efflux and $\mathrm{P}$ ' and between soil $\mathrm{CO}_{2}$ efflux and wind speed are reported for a 5-days period. It is possible to noticed that when there is a rapid increase in $P^{\prime}$ due to a rapid increase in wind speed, the measured efflux is higher than during calm conditions. Takle et al. (2004) found a systematic increase in soil $\mathrm{CO}_{2}$ fluxes with increasing pressure and mean wind speed. Kimball and Lemon (1972) demonstrated the influence of wind on water vapour fluxes through shallow soil but they concluded that diffusion is the dominant process altering soil aeration. Wind can also influence soil $\mathrm{CO}_{2}$ efflux by two other mechanisms: the first is that wind influences the aerodynamic resistance to $\mathrm{CO}_{2}$ transport near the soil surface; the second is that it 
enhances mixing of the atmosphere removing respired $\mathrm{CO}_{2}$ accumulated at the soil surface. An increase in wind speed determines a decrease in $\mathrm{CO}_{2}$ ambient concentration thus enhancing the gradient between soil and atmosphere. As a consequence, a suddenly change in wind condition during lid closure may influence $\mathrm{CO}_{2}$ target concentration thus causing an increase in efflux variability across chambers especially on bare soils.

\section{Conclusions}

The system we described in the present paper shows some advantages and some weakness when compared to other systems: reliable soil respiration measurements as demonstrated by the comparison with the Li-Cor 6400, reduced equipment costs, accuracies at high and low efflux rates, fully automated measurements and good suitability for long term continuous measurements campaigns. In particular, the vent design proposed by $\mathrm{Xu}$ et al. (2006) and implemented in the system allows the pressure to vary as gusts of wind cause the pressure within the surface soils to vary thus to measure effluxes representative of the entire ecosystem. As far as weaknesses are concerned, the critical aspect of the measurement is the $\mathrm{CO}_{2}$ target concentration. In fact, in extreme conditions such as those during the long term campaign presented in this paper (i.e. absence of canopy, bare soil), gusts of wind during lid closure can influence the $\mathrm{CO}_{2}$ target concentration thus causing an increasing efflux variability across chambers.

\section{Acknowledgements}

This work was financially supported by the European Commision through a "Carbon.Pro" CADSES project, the Italian Research Project "CarboItaly" the MIURPRIN number 2005071990 and a Regione Friuli Venezia Giulia Fellowship for G.A.

\section{References}

Baldocchi D.D., Meyers T.P. 1991. Trace gas exchange at the floor of a deciduous forest: I. evaporation and
$\mathrm{CO}_{2}$ efflux. Journal of Geophysical Research, 96:7271-7285.

Davidson E.A., Savage K., Verchot L.V., Navarro R. 2002. Minimazing artifacts and biases in chamberbased measurements of soil respiration. Agricultural and Forest Meteorology, 113:21-37.

Hutchinson G.L., Livingston G.P. 2001. Vents and seals in non-steady-state chambers used for measuring gas exchange between soil and the atmosphere. European Journal of Soil Science, 52:675-682.

Hutchinson G.L., Livingston G.P. 2002. Gas flux. In: Dane J.H., Topp G.C. (eds.): Methods of Soil Analysis: Part 1. Physical Methods. $3^{\text {rd }}$ ed., 1159-1182. Soil Science Society of America, Madison, Wisconsin.

Hutchinson G.L., Mosier A.R. 1981. Improved soil cover method for field measurement of nitrous oxide fluxes. Soil Science Society American Journal, 45:311316.

Kimball B.A., Lemon E.R. 1972. Theory of soil air movement due to pressure fluctuations. Agricultural Meteorology, 9:163-181.

LI-COR 2004. LI-8100 automated soil $\mathrm{CO}_{2}$ flux system instruction manual. LI-COR, Inc. Lincoln, Nebraska.

Livingston G.P., Hutchinson G.L. 1995. Enclosure-based measurement of trace gas exchange: applications and sources of error. In: Matson P.A., Harriss R.C. (eds.): Biogenic Trace Gases: Measuring Emissions from Soil and Water, 14-50. Blackwell Science, Cambridge.

Pumpanen J., Kolari P., Ilvesniemi H., Minkkinen K., Vesala T., Niinisto S., Lohila A., Larmola T., Morero M., Pihlatie M., Janssens I., Yuste J. C., Grunzweig J. M., Reth S., Subke J. A., Savage K., Kutsch W., Ostreng G., Ziegler W., Anthoni P., Lindroth A., Hari P. 2004. Comparison of different chamber techniques for measuring soil $\mathrm{CO}_{2}$ efflux. Agricultural and Forest Meteorology, 123, 3-4:159-176.

Schlesinger W.H. 1977. Carbon balance in terrestrial detritus. Annual Review of Ecology and Systematics, 8:51-81.

Takle E.S., Massman W.J., Brandle J.R., Schmidt R.A., Zhou X., Litvina I.V., Gracia R., Doyle G., Rice C.W. 2004. Influence of high-frequency ambient pressure pumping on carbon dioxide efflux from soil. Agricultural and Forest Meteorology, 124:193-206.

Xu L., Furtaw M.D., Madsen R.A., Garcia R.L., Anderson D.J., McDermitt D.K. 2006. On maintaining pressure equilibrium between a soil $\mathrm{CO}_{2}$ flux chamber and the ambient air. Journal of Geophysical Research, 111, D08S10, doi:10.1029/2005JD006435.

$\mathrm{Xu}$ M., Qi Y. 2001. Soil surface $\mathrm{CO}_{2}$ efflux and its spatial and temporal variations in a young ponderosa pine plantation in northern California. Global Change Biology, 7:667-677. 